\title{
Description of age, sex and site distribution of large bowel cancer in the middle belt of Nigeria
}

\author{
B. M. Mandong and *A. Z. Sule
}

Departments of Pathology and *Surgery, Jos University Teaching Hospital, Jos, Plateau State

Reprint requests to: Dr B.M. Mandong, P.O. Box 887, Jos Plateau State

\begin{abstract}
Aims/Objective: To determine the distribution of bowel cancer with special emphasis on age, sex and site.

Methods: One hundred and sixty cases of histologically confirmed large bowel cancers at Jos. University Teaching Hospital between January 199l - 2000 December were reviewed. The records were collected from the registry of histopathology laboratory. Information regarding sex, age and site of cancers in the large bowel were extracted from referral forms and case notes.

Results: The cancers occurred more commonly between the ages of 31 and 60 years. The distribution showed that more men were affected than women. The rectum was the commonest site, which accounted for $56.9 \%$ followed by colon $32 \%$, Caecum $8 \%$ and anal canal $3 \%$. The colonic cancers were more common in female than male, accounting for $56.9 \%$ and $43.1 \%$ respect vely. Adenocarcinoma was the commonest histological type occurring in 90 percent of cases. None of the resected specimens could reveal a case of familial polyposis. Two cases of non-Hodgkin Lymphoma were recorded and one was in the youngest patient aged 10 years. There were histological evidence of schistosomiasis in two caecal and one rectal adenocarcinoma in this series.

Conclusion: This study showed that bowel cancers are not rare as previously believed. The patients also present at a younger age in our population. Routine screening for bowel cancer in all risk patients should be carried out regularly so as to detect cancer early.
\end{abstract}

Key words: Cancer, large bowel, middle belt, Nigeria

\section{Introduction}

Globally, the large bowel is the second commonest site for malignant diseases of the gastrointestinal tract. ${ }^{1,2}$ In U S A and Europe the incidence of bowel cancer is reported to account for $10.2 \%$ of all cancers in males and $11.1 \%$ of all female cancers. ${ }^{1.2}$ The incidence of large bowel cancer is said to be low in Africa and Asia. ${ }^{1-10}$ However in these low incidence areas the malignant neoplasm observed in younger age groups. The histological subtypes is Adenocarcinoma, with higher proportion of non-mucinuos adenocarcinoma. ${ }^{3-12}$ Studies in some centres in 
Nigeria confirm that large bowel cancers are not only common, but occur in younger age groups in contrast to what obtains in developed Nations of America and Europe. 1. 2. $10-12$ In recent years the mortality rate for large bowel cancer has been increasing and this may be due to delay in the diagnosis. 8.13 .14

The aetiopathogenesis of bowel cancer is not known, but heredity, diet and other environmental factors have been implicated. The dietary factor receiving attention as predisposing to a higher incidence of cancer are excess energy intake relative to requirement, low content of unabsorbable vegetable fibres, high content of refine carbohydrates, red meat and decreased intake of micronutrients. It is theorized that reduced fibre content leads to decreased stool bulk, increased transit time in the bowel and altered bacterial flora in the intestine. Potentially toxic (carcinogens) products are therefore present in higher concentration in the small stools and are held in contact with the bowel for a long time. ${ }^{1.2,8-14}$ Various types of colonic polyps and ulcerative colitis. which are associated with increased risk of bowel cancer, are reported to be uncommon in Africans. ${ }^{315,16}$ Anal cancers are relatively uncommon in Europe and America, but are reported to be common in some African countries. ${ }^{3-7}$

The incidence of bowel cancer by age, sex, and tumour site is infrequently "reported. This is the first time this study is

being undertaken and it is intended to form the basis for further studies.

\section{Materials and methods}

This is a histopathological basis of distribution of large bowel cancers.

One hundred and sixty cases of histologically confirmed large bowel cancer in patients at the Jos University Teaching Hospital (JUTH) between January 1991 and December 2000 were reviewed. Jos University Teaching
Hospital is a Federal Tertiary Health Institution in Central Nigeria and receives surgical biopsy specimens from all government and private hospitals in this region. This region has an estimated population of 12.2 million, constituting approximately $14 \%$ of Nigeria's population. The records were available for analysis in the Histopathology and Medical Records Departments. Relevant data on age, sex and site of tumour in the large bowel, and the histological diagnosis were extracted from the case notes. The findings were then analyzed.

\section{Results}

There were 160 patients with large bowel cancer in this 10-year review giving a yearly incidence of 16 per year. Colorectal carcinoma was present in 146 of them. Ninety-five of them were male, while 65 were females with a male to female ratio of $1.5: 1$. The ages of the patients ranged from $10-80$ years, with a mean of 42.9 years. The youngest patient was 10 years old and the oldest 80 years. The distribution of bowel cancer according to the age profile of the patients is shown in Table 1 . The disease was commonly seen between the ages 31 and 60 years. The distribution of the disease according to age category shows that large bowel cancer occurred more in men than women.

The rectum was the commonly affected site in large bowel cancer $(56.9 \%)$. The colon was involved in $32 \%$ while the caecum and anal canal were affected in only 8 and 3 percent respectively. Sixtyone percent of all rectal cancers were in men, while 38.5 percent occurred in women. However, in the colon, the reverse was the case with 56.9 and 43.1 percent occurring in females and males respectively.

Adenocarcinoma was the commonest histological type occurring in 90 percent of cases. None of the resected specimens could reveal a case of familial polyposis. 
Squamous cell cancer occurred in $4.4 \%$ of patients and all were in the anal canal. These were present in patients 40 years and above. Of the two cases of Non-Hodgkin's Lymphoma (low grade lymphoma), one, was in the youngest patient aged 10 years. There were histological evidences of schistosomiasis in two cuecal and one rectal adenocarcinomas in this series.

Table 1: Age profile of paticnts with large bowel cancer in Jos

\begin{tabular}{llll}
\hline Age (Years) & Total No. & & \\
\hline $9-10$ & 1 & M & F \\
$11-20$ & 18 & - & 1 \\
$21-30$ & 24 & 12 & 6 \\
$31-40$ & 29 & 14 & 10 \\
$41-50$ & 39 & 22 & 17 \\
$51-60$ & 20 & 11 & 9 \\
$61-70$ & 18 & 13 & 5 \\
$71 .-80$ & 11 & 7 & 4 \\
\hline
\end{tabular}

Table 2: Distribution of large bowel cancer according to site

\begin{tabular}{lllllll}
\hline $\begin{array}{l}\text { Anatomical } \\
\text { Site }\end{array}$ & $\begin{array}{l}\text { Total } \\
\text { No. }\end{array}$ & $\begin{array}{l}\% \text { of total } \\
\text { cases }\end{array}$ & \multicolumn{1}{l}{ Sex Distribution } & & \\
\hline Rectum & 91 & 56.9 & 56 & 61.5 & 35 & 38.5 \\
Colon & 50 & 32.1 & 21 & 43.1 & 29 & 56.9 \\
Caecum & 12 & 8,0 & 8 & 72.9 & 4 & 27.1 \\
Anal canal & 7 & 3.0 & 4 & 60 & 3 & 40 \\
Total & 160 & 100.0 & 89 & - & 71 & - \\
\hline
\end{tabular}

Table 3: Histological type of large bowel cancer in Jos

\begin{tabular}{lll}
\hline Histological Type & No. & $\%$ \\
\hline Adenocarcinoma & 144 & 90.0 \\
Lymphoma (Non-Hodgkin's Lymphoma) & 2 & 1.2 \\
Leiomyosarcoma & 7 & 4.4 \\
Anorectal Squamous Cell Cancer & 7 & 4.4 \\
Total & 160 & 100 \\
\hline
\end{tabular}




\section{Discussion}

Large bowel cancer was thought to be rare in Africa. 3,7,9 The reported incidence varies from $0.2-4.4 \%$. A total of one hundred and sixty colon cancers were seen over ten-year period. This constituted $8.8 \%$ of all cancers reported over the same period. This figure is higher than what is in Zaria and Ibadan. ${ }^{3-9}$

In this study male: female ratio was 1.5 : 1 comparable to what is obtained in Lagos $1.1: 1$, and is in contrast to higher figures reported from other African countries 2.8:1 and India $1.67: 1,{ }^{3-9,18}$

The mean age for this study was 42.9 years .In some centres in Nigeria is reported to be $46-47.3$ years. All these figures confirm that large bowel cancers occur earlier in Africa in contrast to what obtains in developed nation of America and Europe with mean age presentation at the 7 th decade of life. $210-14$

The anatomic distribution shows that rectum accounted for $56.9 \%$ the remaining colon $32 \%$ caecum $8 \%$ and anal cancer $3 \%$. Higher figures have been reported from Zaria rectum $62 \%, 22.9 \%$ rest of colon and 10.1 anal canal. From this study cancer of large bowel occurred predominantly on the rectal region. Previous report from Ibadan and Zimbabwe as reported in a paper of Stephen ${ }^{4}$ that sigmoid was the commonest site of colonic cancer. Subsequent report shows that rectum is the commonest site of colon cancer. ${ }^{12,15}$ Cancer of colorectum in Jos University Teaching Hospital occurred predominantly in Male, while colonic cancer occurred predominantly in females. This is similar to reports from Zaria, Lagos, Ibadan, Zimbabwe and Zaria respectively. ${ }^{3,4,5-9,16}$

Adenocarcinoma was the commonest histological subtypes and accounted for $90 \%$. This is comparable to Lagos $90.3 \%$ Uganda $65.2 \%$. In this study anal squamous cell carcinoma was $4.4 \%$ of all large bowel cancer. This is lower than reported cases from Lagos $5.3 \%$ Zaria
$10 \%$. In contrast to what obtains in America and Europe 3-4\%. ${ }^{13.14}$

Lymphoma constituted $1.2 \%$ and was seen in 10 and 18 year old female. Lymphoma is not common in the large bowel. The figure is higher in developed Nations.

There were histological evidence of schistosomiasis in two caecal and one rectal adenocarcinoma. There is a possibility of this being a co-incidence, but again it raises the question as to whether there is any association between large bowel carcinoma and large bowel schistosomiasis as has been asserted. 1

Large bowel cancer was once thought to be rare in Africans, but present study and similar studies in Nigeria and other African countries show that the disease is not uncommon. The disease present at a younger age in our population. The rectum still remains the commonest affected site with more male than female affected at all age categories.

\section{References}

1. Archampong EO, Ogunbiyi T, Annamunthodo H, Foli AK, Badoe EA, Aina AO. Small and large intestine (including Rectum and Anus). In: Badoe EA, Archampong EO, Jaja MOA (eds). The principles and practice of surgery, including pathology in the tropics. Ghana Publishing Corporation, Accra. 1994; 564-636.

2. Jam MC. The gastrointestinal tract. In: Cotran RS, Kumar V, Collins T. (eds) Robbins pathologic basis of disease. Saunders, Philadelphia. 1999; 827843.

3. Ameh EA, Nmadu PT, Rafndadi AH et al. Colorectal and anal cancers in Zaria a clinico-pathological study. Gastrointestinal cancer 1993; 11-15.

4. Elesha SO, Owonikoko TK. Colorectal neoplasms: a retrospective 
study. East Afr Med J 1998; 75: 718 723.

5. Ajao OG, Grillo AI et al. Colon and rectal neoplasm in a tropical African population: an overview report. East Afr Med J 1994; 30: 640-643.

6. Ogunbiyi JO. Epidemiology of cancer in Ibadan: tumours in adults. Archives of Ibadan Medicine 2000; 1: 9-12.

7. Ajao OG. Colon and rectal neoplasm in a tropical African population. Int Surg 1979; 64: 47-52.

8. Garfunkel L, Mushinshi M. Cancer incidence, mortality and survival: trends in four leading sites. State Bull Metrop Insur Co, 1994; 75: 9-27.

9. Ajao OG. Adenuga MO, Ladipo JC. Colorectal carcinoma in patients under 30 years: a review of 11 cases. $J$ R Coll Surg Ldin 1988; 33: 277-279.

10. Martha I.S, Garry DF, John DP, Sandra E. Bete JC, Wade S. A description of age. sex and site distribution of colon carcinoma in three gengraphic areas. Cancer 1996; 78: $1606 \cdots 16670$.

11. Ken T, Shosei I, Akihiro M, Yutaha Y,
Shigeyuhi N, Kazuo S. Annual changes in colorectal carcinoma incidence. Cancer 1996; 78: 1187 1194.

12. McMichael AJ, Gilles GG. Colorectal cancer. Cancer Surv 1994; 19-20: 7798.

13. Dukes CE. Surgical pathology of rectal cancer. Proc R Soc Med 1944; 37: 131-144

14. Theodore RS. Cancer of the large intestine. In: Current surgical diagnosis and treatment. Lange, Connecticut. 1991; 643-651.

15. Oettle AG. Cancer in Africa, especially in regions South of the Sahara. J Natl Inst 1964; 33: 383-436.

16. Stein CM, Gelfand, MacDougall CN. Cancer of colon and rectum in Zimbabwe. Centr Afr J Med 1985; 31 ; 88-90.

17. Owor R. Carcinoma of colon and rectum in Uganda Africans. East Afr Med J 1983; 60: 228-330.

18. Shah A, Wani NA. A study of colorectal adenocarcinoma. Indian J Gastroenterol 1991; 10: 12-13. 